\title{
An unusual age presentation of mature cystic teratoma: a case report
}

\section{Sindhura Inkollu*, Ashwini Nelavelli, Shyam Mohan Rao Merugu}

Department of Obstetrics \& Gynaecology, Alluri Sitarama Raju Academy of Medical Sciences, Eluru, Andhra Pradesh, India

Received: 05 June 2015

Accepted: 10 July 2015

\section{*Correspondence:}

Dr. Inkollu Sindhura,

E-mail: dr.sindhu216@gmail.com

Copyright: ( $\odot$ the author(s), publisher and licensee Medip Academy. This is an open-access article distributed under the terms of the Creative Commons Attribution Non-Commercial License, which permits unrestricted non-commercial use, distribution, and reproduction in any medium, provided the original work is properly cited.

\begin{abstract}
Mature cystic teratoma compromise $20-30 \%$ of all ovarian tumours. They are mostly seen in patients between 20 and 40 years of age and are mostly asymptomatic. Malignancy incidence is high in postmenopausal group. Here, we report a case of mature cystic teratoma presenting unusually in a 65 year old postmenopausal woman with pain abdomen. A 65 year old postmenopausal woman presented with lower abdominal pain of 15 days duration. Upon examination, a mass of size $7 \times 8 \mathrm{~cm}$ felt on bimanual examination. CT showed the same cyst that has a focal enhancing mural nodule with fat density in it. Total abdominal hysterectomy with bilateral salpingo oopherectomy done. Histopathological examination confirmed mature cystic teratoma. Although mature cystic teratoma is rare after 40 years age, especially in postmenopausal women and are usually malignant in that age group, it can have an unusual age presentation at 65 years with benign nature as in our case.
\end{abstract}

Keywords: Mature cystic teratoma, Ovary, Postmenopausal woman

\section{INTRODUCTION}

Mature cystic teratoma is the most common type of ovarian germ cell tumour. ${ }^{1}$ It constitutes $20-30 \%$ of all ovarian tumours. $^{2}$ It is mostly seen in women younger than 40 years age and is seldom seen in postmenopausal women. They are bilateral in $10-15 \%$. Malignancy incidence is low $(1-2 \%){ }^{3}$ Here, we report a case of mature cystic teratoma presenting unusually in a postmenopausal woman of 65 years age.

\section{CASE REPORT}

Mrs.X, a 65year old postmenopausal woman was admitted on 7th Oct 2014 with a history of pain in the right lower abdomen for the past 15 days, which was insidious in onset, dull aching, non-radiating. She reached menopause 20 years back, her previous cycles were normal. She had four term normal vaginal deliveries. Her past and family history was all unremarkable.
On examination, she was moderately built and nourished. Her vital parameters were within normal limits. No lymph nodes were palpable. On abdominal examination, it was soft, no organomegaly and no palpable masses felt. On bimanual examination uterus was atrophic, a regular mass of size 7 X $8 \mathrm{~cm}$ which was freely mobile and cystic in consistency was felt in left fornix. Per rectal examination-rectal mucosa free. Her Haemoglobin was $8.5 \mathrm{gm} / \mathrm{dl}$ and all other haematological investigations were normal. Ultrasonography showed a large mixed echogenic mass of size $7.5 \times 5.4 \mathrm{~cm}$ in the left adnexa and uterus is of size $5 \times 2 \mathrm{~cm}$. CT abdomen showed a large cystic lesion of $7.8 \times 6.7 \mathrm{~cm}$ in the left adnexa with left ovary not seen separately. Focal $1.6 \mathrm{X} 1.0 \mathrm{~cm}$ enhancing mural nodule is noted in it, with fat density within the nodule (Figure 1). Her CA- 125 was 15.86 U/ml. Risk Malignancy Index score was 45. 


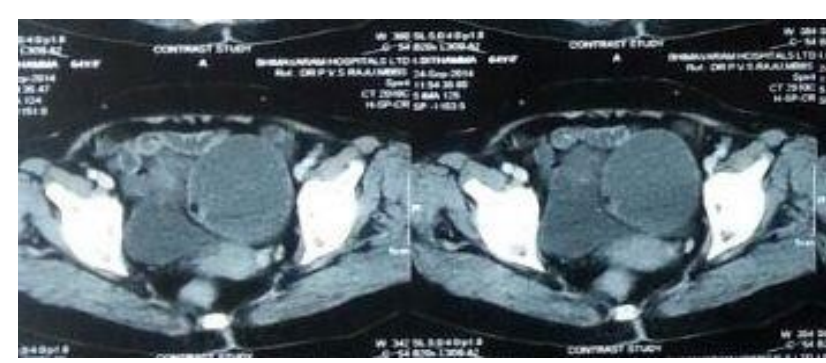

Figure 1: CT image of mature cystic teratoma.

Considering her age, case was posted for laparotomy on $13^{\text {th }}$ October 2014 following blood transfusion. Intraoperative findings revealed a cyst of $7 \times 7 \mathrm{~cm}$ with smooth surface, cystic in consistency (Figure 2). Ovary was not seen separately on left side. Other ovary was normal, uterus was atrophic, no ascites, omentum appeared normal, hepatic surface was smooth. Total abdominal hysterectomy with bilateral salphingo oophorectomy done. Patient made an uneventful recovery.

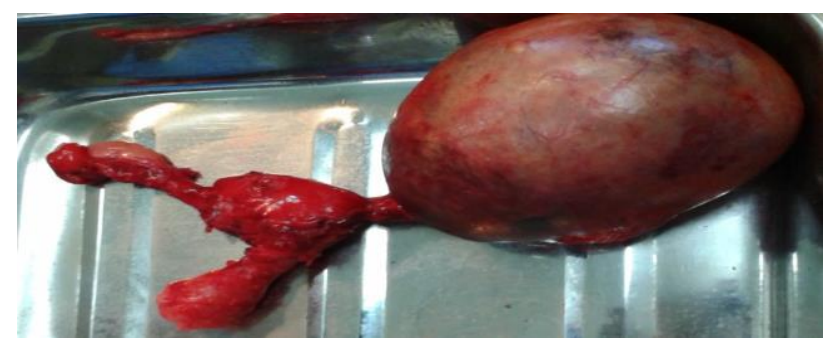

Figure 2: Post-operative specimen showing a cystic lesion arising from left ovary.
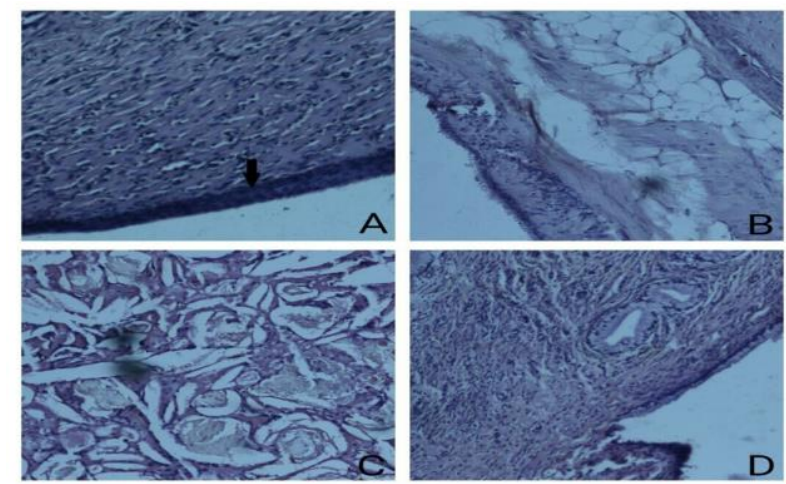

Figure 3: Mature cystic teratoma of ovary (H\&E) (A:

Squamous epithelium, B: Adipose tissue, C:

Cholesterol clefts, D: Glandular elements).

On gross examination a left ovarian cyst of size $10 \times 7 \mathrm{X}$ $3 \mathrm{~cm}$ filled with grey white cheesy material along with few hairs and a focal thickness area of $2.5 \times 2 \mathrm{~cm}$ seen. Histopathological examination showed a mature teratoma of ovary composed of ectodermal elements such as a squamous epithelium; elements from mesoderm such as cholesterol clefts, hair follicles, elements from endoderm as pseudo stratified ciliated columnar epithelium, thyroid follicles and lymphocytic aggregates also (Figure 3 ).

\section{DISCUSSION}

Mature cystic teratomas often referred to as dermoid cyst are the most common germ cell tumours of the ovary. They makeup approximately $20-30 \%$ of ovarian neoplasms. Majority are $5-10 \mathrm{~cm}$ in diameter. They are composed of well differentiated derivatives of three germ layers- ectoderm, mesoderm, and endoderm.4 Mature cystic teratomas are more common in reproductive age group, at 20-30 years and seldom seen in postmenopausal women. ${ }^{5}$ Increasing levels of estrogen and progesterone may explain the increase in size of mature cystic teratoma after puberty and their arrested growth after menopause. In adults they are often detected incidentally either during imaging or other pelvic surgeries. They have a characteristic CT scan appearance with fat or fluid level attenuation and calcification or ossification. Complications of ovarian teratoma include torsion, rupture, and infection. Malignant transformation is low accounting for $1-2 \%$ of cases. This rate increases in postmenopausal women (15\%). ${ }^{6}$ Most common malignancy developing in benign cystic teratoma is squamous cell carcinoma. ${ }^{7}$ Other neoplasms have also been reported.

Elevated CA-125 levels point to malignancy. Because menopausal women have fewer gynaecological diseases that give a false evaluation of CA-125, the test is more sensitive and specific in post-menopausal period. Calculating Risk Malignancy Index, which is a product of the ultrasound scan score, the menopausal status and the serum CA125 levels, is useful in identifying candidates with increased risk of malignancy and any malignancy should be managed expeditiously by staging laparotomy. Canceration of mature cystic teratoma almost always occurs in older age therefore even considering the poor tolerance of elderly patients to surgery, surgery should not be avoided. So total hysterectomy with bilateral adnexectomy is the 1 st choice in post-menopausal women. Any features of malignancy at the surgery should prompt appropriate surgical staging and treatment for ovarian cancer.

In the present case even though CA-125 level is within normal limit, considering her age; we advised CECT of abdomen and pelvis and undertook exploratory laparotomy. HPE findings confirmed the presence of mature teratoma. The literature on mature teratoma in postmenopausal women is limited. There are a few cases reported in retrospective descriptions of isolated cases or small series. ${ }^{6,8}$ Though rare, mature cystic teratoma can have an unusual age presentation in post-menopausal women.

Funding: No funding sources Conflict of interest: None declared Ethical approval: Not required 


\section{REFERENCES}

1. Koonings PP, Campbell K, Mishell DR, Jr, Grimes DA. Relative frequency of primary ovarian neoplasms: a 10 year review. Obstet Gynecol. 1989;74:921-6.

2. Ayhan A, Bukulmez O, Genc C, Karamursel BS, Ayhan A. Mature cystic teratomas of the ovary: case series from one institution over 34 years. Eur J Obstet Gynecol Reprod Biol. 2000;88:153-7.

3. Ozgur T, Atik E, Silfeler DB, Toprak S: Mature cystic teratomas in our series with review of literature and retrospective analysis. Arch Gynecol Obstet. 2012, 285:1099-1101.

4. Sah SP, Uprety D, Rani S. Germ cell tumours of the ovary: A clinicopathologic study of 121 cases from Nepal. J Obstet Gynaecol. 2004;30(4):303-8.

5. Ulbright TM. Germ cell tumours of the gonads: a selective review emphasizing problems in differential diagnosis, newly appreciated, and controversial issues. Modern Pathology. 2005;18(2):S61-S79.

6. Wei F, Jiang Z. Yan C. Analysis of 20 mature ovarian cystic teratoma cases in postmenopausal women. Chin Med J (Engl). 2001;114:137-8.

7. Rim SY, Kim SM, Choi HS. Malignant transformation of ovarian mature cystic teratoma. Int J Gynecol Cancer. 2006;16(1):140-4.

8. Gordon A, Rosenhein N, Parmley T, Bhagavan B. Benign cystic teratomas in postmenopausal women. Am J Obstet Gynecol. 1980;138:1120-23.

Cite this article as: Inkollu S, Nelavelli A, Merugu SM. An unusual age presentation of mature cystic teratoma: a case report. Int J Reprod Contracept Obstet Gynecol 2015;4:1234-6. 